\title{
Japanese Chin
}

National Cancer Institute

\section{Source}

National Cancer Institute. Japanese Chin. NCI Thesaurus. Code C53932.

The Japanese Chin is a small spaniel with a short, broad face, and a soft, feathered coat. A thick ruff covers the neck and chest. The nose is wide and the nostrils open. The upside-down, v-shaped ears are well covered with hair. The coat comes in white with colored patches, most often black, but sometimes red, yellow, orange, sable or brindle. Height: 7-11 inches (18-28 cm.) Weight: up to 9 pounds (4 kg.) There are two classes of Japanese Spaniels: under 7 pounds, and over 7 pounds. 